\title{
An Inclusive Perspective on Transition to Primary School
}

\author{
CHRISTINE STEPHEN \& PETER COPE \\ University of Stirling, Scotland
}

\begin{abstract}
Despite a commitment to inclusion and equality in the national priorities for school education in Scotland, the experience of children as they move from pre-school to primary school falls short of being an inclusive experience for all, and some children are at risk of becoming disengaged from education at the beginning of their school career. In this article, the process of transition to school is examined through the 'lens' of inclusion. The data comes from a study of the experience of 27 children during their first year in school. It was clear that teachers saw transition to school as a one-way process in which children had to 'fit in' to school, and did not see it as their task to respond to the diversity of children's preferences, previous experiences or background. It is argued that the teachers' approach is akin to adopting a medical or individual model of inclusion (locating the difficulties in the child) rather than a social model that looks for the source of difficulties in the mismatch between the environment and the child's needs. Adopting a social model allows for barriers to inclusion at the beginning of primary school to be identified and some of the barriers that children experience are explored, with illustrations from the data.
\end{abstract}

\section{Introduction}

One of the five priorities for school education approved by the Scottish Parliament in 2000 is 'Inclusion and Equality', defined as being 'to promote equality and help every pupil benefit from education' (Scottish Executive Education Department, 2001). We will argue in this article that, despite this policy objective, the experience of beginning school falls short of being an inclusive experience for all children. We recognise that schools must pursue multiple objectives simultaneously (there are, after all, five national priorities for education in Scotland) and that there may be tensions or conflict between these objectives. Furthermore, schools in Scotland are managed in a culture 
that stresses attainment and accountability. Whilst not seeking to ignore or negate these features of the environment in which teachers work, our purpose in this article is to focus on the view of transition (its opportunities and risks) that is revealed when the experiences of children and the perspectives of their teachers are examined in terms of two ways of thinking about inclusion.

Barton (1997) argues that inclusive education must be characterised by institutional change or adaptation:

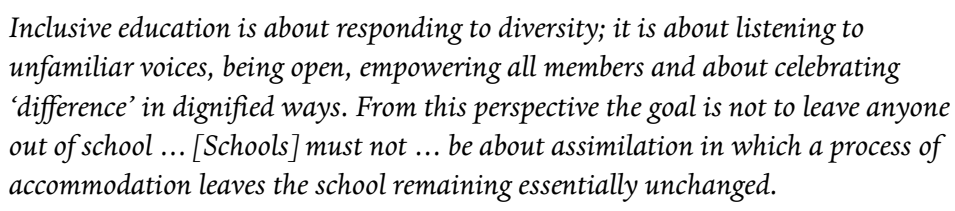

Although he was not writing specifically about transition to school, Barton's argument seems equally (even particularly) applicable to the period when young children begin school. Each Primary 1 (P1) class offers an opportunity to establish a new and distinctive community of learners that is responsive to the diversity of experience and the preferences of its members in a way that will foster the inclusion of all in the educational project in which they will be compulsorily engaged for the seven years of primary school. The pupils who are gathered into a typical first class in primary school (P1) are a heterogeneous group. Some of them may know each other but they will all be largely unknown to their teacher. Children begin primary school with different experiences of home and family circumstances and of community life. They may come from diverse cultures and have had experience of different forms of pre-school provision. However, regardless of the form of pre-school provision that they attended (half-day or full-day, in the public, private or voluntary sector), in terms of pedagogy and relationships, these settings will have been more like each other than like a school class.

This article begins with a description of our study of the experience of transition from pre-school to school, followed by a report of the findings. These findings prompted us to look at the process of transition in the terms suggested by two different models of inclusion, that is, the individual or medical model and the social model. We will relate our findings to each of these models in turn. As adopting the social model requires the identification of barriers to inclusion, we go on to examine the kinds of barriers experienced by children as they begin primary school. The article concludes with a summary of the advantages of thinking about transition in terms of the social model of inclusion and offers some suggestions about the ways in which this approach could be adopted in schools.

\section{The Study: sample and research methods}

Our empirical evidence was gathered as we followed 27 children through their year in P1.[1] This exploratory study was designed to contribute to an 
understanding of the way in which children experience the move to primary school and the perspectives of their parents and teachers. It looked at three areas of change in the children's lives, that is, the move from playroom to classroom, alterations in the out-of-home care arrangements necessitated by transition to school, and children's developing concepts of learning and 'success' in the classroom context. (The project is reported in full in Stephen et al, 2003.) In this article we report only on the evidence gathered about the transition to the primary school learning environment. Three questions guided this aspect of the study.

- What are the features of school life that give children satisfaction and advantage or dissatisfaction and difficulty as they begin primary school?

- To what extent does the kind of pre-school provision experienced relate to the child's early experience of school, and what advantages or disadvantages (in terms of settling into school life and learning) are associated with different models of pre-school provision, from the perspective of P1 teachers, parents and children?

- What factors appear from the analysis to be important in influencing the success of transition from pre-school to school?

The sample children were aged from 4 years 6 months to 5 years 5 months when they began school (the usual age range for children in P1 in Scotland). All of the children had taken part in a study which we carried out during the previous year when we explored the experience of 43 three and four year-olds (along with the views of their parents and pre-school practitioners) as they attended varying forms of all-day pre-school provision (Stephen et al, 2001). It should be acknowledged that our sample was opportunistic, rather than representative, as it arose from the criteria used to select the sample for the allday provision study. Nevertheless, this study offered a welcome opportunity for a longer-term look at children's educational experiences. The data that we had already collected during the children's last year in pre-school provision (the perspectives of children, parents and practitioners and structured observations of playroom behaviour) allowed us to compare their experience in the pre-school setting and school classroom.

The children in our study had received all-day provision from local authority or private nurseries or by some combination of time in a local authority nursery school or class, private nursery, or care from a nanny or childminder. (Five half-day sessions only at a local authority nursery school or class is a much more typical experience for three and four year-olds in Scotland.) As part of their 'all-day package', 20 of the children in our sample did attend a local authority setting for five half-day sessions each week and the other seven children attended private sector settings that were in partnership with their local authority and, therefore, subject to the same curricular expectations. Although some had chosen to use private sector provision and others local authority provision during their child's pre-school years, all of the parents selected a local authority primary school. 
The data were collected in two phases during the children's first year in school. Phase 1 was a retrospective look at the arrangements for transition made towards the end of their pre-school year and during their first weeks in school. The second phase of data collection was carried out towards the end of the school year. The experiences of children were investigated through audiorecorded conversations with the participants and observations of their behaviour in the classroom and during breaks. For each observation period we recorded:

- the classroom or playground context (e.g. whole class adult led numeracy work, individual work e.g. drawing, small group synthetic phonics, free play outside);

- the child's actions (e.g. finds letters on magnetic board, answers questions, speaks to other children);

- observable indicators of child's affective state and level of engagement (e.g. laughs, focuses on board, looks at other speaking, hits out).

In categorising children's affective state we used the behaviour classification system developed during our study of all-day pre-school provision. Children's observable behaviour is inferred to indicate satisfaction and positive affect or dissatisfaction and negative affect (see Stephen et al [2001] for details of the classification).

During Phase 1 our conversations with children focused on their reactions to school, after-school care and the first weeks of school. They were prompted by line drawings of faces portraying four 'states': happy; sad; cross or angry; tired or sleepy. For example, conversations were begun by questions such as 'Do you ever have a face like this at school?' or 'What might make you have a face like this at school?' This technique for eliciting the perspectives of children was selected as the most engaging and productive of the four methods piloted for the all-day provision study. Children's reactions during that study and the transition study reported here suggest that it is both a useful research tool and a process that the children find manageable and enjoyable. Our questions were more direct during Phase 2 and included enquiries about progress with schoolwork, being in groups in the class and school rules. We were careful, however, to avoid 'why' questions, as children in the age range covered by our sample find these questions challenging. On both occasions the children were told that others wanted to know what they thought about school, were introduced to the use of the tape recorder, invited to switch the machine on, to switch it off when they wanted to and to hear their own recording. The conversations with each child were fully transcribed.

The interviews with adults were semi-structured and covered a number of domains dictated by the research questions and the phase of the study. Each adult interview was audio-recorded and transcribed in full. Teachers were interviewed face to face but interviews with parents were conducted by telephone at a convenient time. As well as talking to teachers about the children from our sample that were in their classes, we took the opportunity 
to ask about the expectations that they had for children in general during their first year of school. Parents and teachers agreed to quotations from their interviews (ascribed to role only) being used in the report and subsequent publications. Great care was taken to maintain the confidentiality of the local authorities, schools, teachers and families who participated. When individual children are referred to in this article, pseudonyms are used. The list of research sites and participants remains known only to the researchers. In line with usual practice for work commissioned by the Scottish Executive Education Department, a summary of the research findings (written largely for practitioners) has been published and was sent by the researchers to all participants before the publication date (Stephen \& Cope, 2003).

In the section that follows we report on data about transition gathered mainly, but not exclusively, during Phase 1. The analysis of the teachers' responses in particular led us to consider further the ways in which they thought about transition and their role in the process.

\section{Research Findings: the experience of transition}

There is a growing literature about the ways in which schools (in liaison with pre-school settings) can offer information and induction experiences that ease the path of transition for children and their parents (e.g. Fabian, 2002; Margetts, 2002). All the children and parents in our study were given some opportunity to become familiar with the physical environment of the school, the curriculum and the way in which the school and the children's day was organised. But the content of these events and visits was largely concerned with structural or organisational matters and the mechanics of entry to school. The school and its expectations were introduced to parents and children but the accounts of parents and teachers made it clear that there was much less attention paid to teachers learning about the new members of their class and very limited use made of the written records transferred from pre-school.

Only about half of the 20 teachers interviewed made reference to the transition documents sent from nursery and only four commented positively on the records they received and described how they had used them. This finding endorses the view commonly held by pre-school practitioners that schoolteachers disregard their reports on individual children as they move to school (Wilkinson et al, 1999). Although there have been national curriculum guidelines shaping pre-school provision for four year-olds since 1997 (Curriculum Framework for Children in their Pre-school Year, Scottish Office Education and Industry Department [SOEID], 1997) and for 3-5 year-olds since 1999 (Curriculum Framework for Children 3 to 5, Scottish Consultative Council on the Curriculum [SCCC], 1999), the primary school teachers of children in our sample were largely unconcerned with their pupils' developmental progress at transition (with the exception of some aspects of social and emotional development). They did not seek information about 
children's progress in specific curricular areas, nor did they have any expectations about children's curricular experiences in pre-school.

The children's retrospective accounts of their early weeks in school were less fulsome and differentiated than their accounts of current experiences. Most made general comments such as 'fine', a few recalled specific events but only one described her own unhappiness. (It is our experience that, in general, 3-6 year-olds respond in a more articulate way to invitations to describe and explain current events than to requests to recall or evaluate experiences.) The majority of parents described the period when their child settled into school as unproblematic or indeed as a positive process, something looked forward to and enjoyed. A few identified some difficulties or hesitation during the first few weeks of school but the parents of two children recognised a more lasting dislike of or lack of adjustment to school.

Parents tended to ascribe any initial difficulties to the time when their child arrived at school and had to separate from them. In contrast, teachers focused on the way in which the children settled into the classroom and learning activities. Their responses suggested that they thought about children in the four categories described in Figure 1.

IERA MUFL

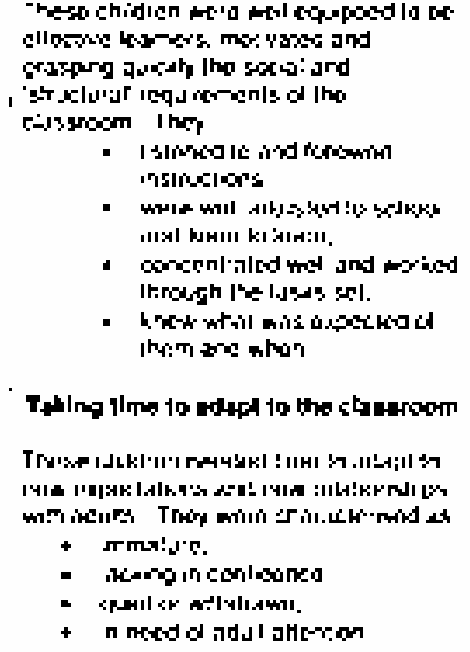

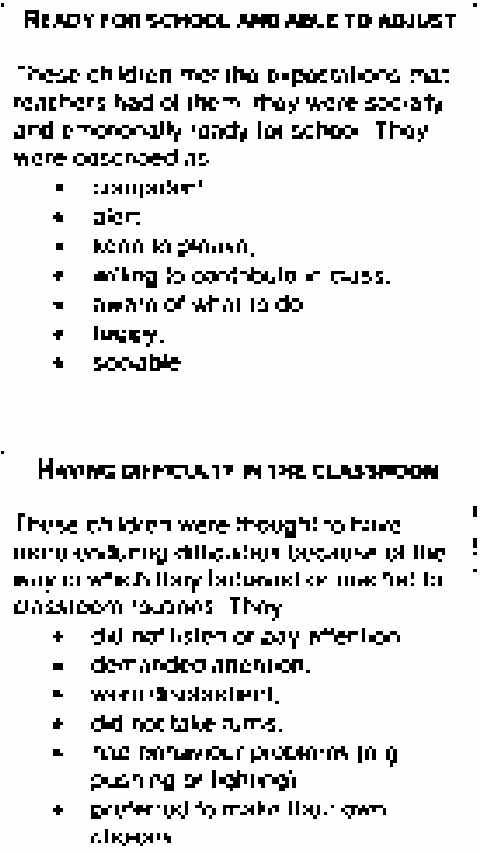

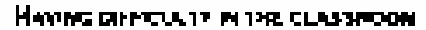

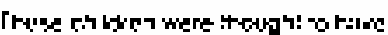

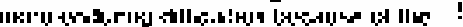

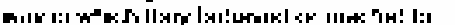

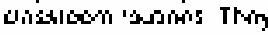

+ -

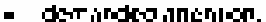

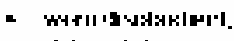

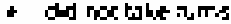

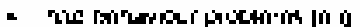

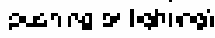

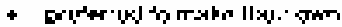
AItHath

Fig. 1. Characteristics ascribed by teachers to children beginning school. 
Four children were described by their teachers as 'ideal' or very near to being an ideal pupil. These children were perceived to be well equipped to be effective learners. They were motivated and quickly grasped the social and 'structural' (e.g. routines and timetables) requirements of the classroom. A further 12 children were considered to have 'adjusted well' to school and to have met the expectations that teachers had of them, in terms of social behaviour and a readiness to learn. Five children were described by their teachers as 'needing time to adapt to the classroom', new expectations of them and new relationships with adults. A further six were thought to have 'difficulties in the classroom' because of the way in which they behaved or the way in which they reacted to classroom routines and expectations. The problems with children's behaviour identified during the first few weeks proved to be enduring for three children (at least from the perspective of their teachers). Three others were thought to be overcoming their difficulties with school discipline and structure and to present fewer problems in class by the end of their first year. On the other hand, the behaviour of two children not identified initially as presenting difficulties had given their teachers cause for concern during the year.

For most of the children in our sample then, transition seemed to be satisfactory. But some were not happy at school and were described by their parent, teachers and sometimes in their own responses as disliking school or finding it difficult to 'fit in'. While teachers might recognise that a particular child found aspects of classroom life difficult or preferred other forms of organisation, they did not talk about adapting their practice in response. As teachers talked about the sample children in their classrooms and about characteristics that made transition to school easier for children in general, the 'one way' nature of their conception of transition became apparent. Ideal or well-adjusted children listened to and followed instructions, worked through tasks set, learned school routines and followed them, were keen to please, sociable (but not too talkative) and possessed a suitable degree of independence. In contrast, children who were less confident or outgoing, wanted adult support or attention, did not pay attention to adults or the rules for classroom behaviour, did not want to do the work given and preferred to make their own choices were thought of as posing difficulties, for teachers and for themselves.

Teachers' responses to our questions about the characteristics they hope for in any child starting school mirrored those above. They made no mention of expectations of the children's development of language and communication skills, knowledge and understanding of the world or any other curricular area (with the exception again of some aspects of emotional, personal and social development). Rather, they wanted children to come to school willing and able to listen, motivated to learn and responsive to adults, able to socialise and cooperate with their teacher and other children, although not overconfident, and able to recognise the authority of the teacher. They wanted children to be ready for the kind of learning environment they saw as desirable in primary 
school, that is, a structured and disciplined environment. To this end the teachers expressed a view that nursery classes offered a better preparation for primary school than other forms of pre-school provision as they made children more familiar with school routines and resources and pupils were better trained' for classroom life.

Two things seemed clear to us. First, children were expected to 'fit in' at school and secondly, when children had difficulty with this transition teachers ascribed the problems to the child, not the school. For example, teachers said:

he can be very strong willed ... he is becoming his own worst enemy ... he feels

that he has got to prove himself. (Teacher: Jack)

There are certain things about her that [I] really get quite frustrated with ... She doesn't seem to have this sense of authority that a lot of children have. (Teacher: Olivia)

... children that are either too young or just not developmentally ready to cope with that sort of structure. (Teacher: Roli)

There appeared to be no alternatives for children who did not fit into the typical P1 classroom or behave there in ways that matched the expectations of their teachers. Indeed, the reaction of one teacher to children arriving in P1 with alternative expectations of learning environments acquired in pre-school had been to act to 'suppress' such ideas:

They are used to choices in nursery. This year I was very hard on them when they

first came in. I have had difficult times when they want to choose and be like at

nursery. This year I was harder on them at the beginning. (Teacher: Isla/Emily)

In summary then, the transition experiences of the children we followed and the perspectives of their teachers suggested that responding to the diversity of pupils by adapting to accommodate them is not the way in which schools construe the process. In the classrooms that children in our sample attended transition was thought of as a one-way process through which children learned about and became accustomed to the kind of educational provision on offer. This perspective carries the accompanying risk that those who do not become rapidly accustomed to school are at risk of disaffection from school and learning at the beginning of their academic careers. But looking at the process through the lens of inclusion suggests alternative ways of constructing the process, and it is to a discussion of two ways of thinking about inclusion that we now turn, considering first, the medical or individual model and secondly, the social model.

Two Models for Thinking about Inclusion: locating the difficulty in the child or the environment

The literature on understanding disability offers a model for thinking about inclusion that encapsulates the thinking of the teachers we interviewed and 
suggests an alternative that offers a way of moving beyond the 'fitting in' approach. Oliver (1996) distinguished between the individual or medical model of disability and the alternative social model. We suggest that the teachers in our study were adopting an individual or medical model. They ascribed the difficulties that children experienced to features of the child's personality, behaviour or inappropriate expectations or preferences (e.g. Kylie had poor concentration, Ravi had behaviour problems). They located the 'cause' of the problem in the child and it then follows that this is where any change or adaptation must be located. Such an approach has an obvious appeal to individual teachers (although 'difficult' children remain in their classrooms) and to schools as institutions. Bernstein (1996, p. 11) is clear that schools individualise failure (reducing the threat to 'myths of hierarchy' and charges of ineffective teaching) by attributing it to 'inborn facilities (cognitive, affective) or to the cultural deficits relayed by the family which come to have the force of inborn facilities. While such an approach may allow schools to remain unchanged and continue in ways that may be manageable for many children, it does nothing to address the inequalities experienced by children who fail to 'adapt' and who will (at least during the period of compulsory education) continue to challenge, or be excluded from, the schools in which they are placed.

The alternative social model perspective does not deny problems but locates the cause of the problem in society's failure to provide appropriate services or adapt to meet the needs of individuals. In the case of transition to primary school, a 'social model' approach would lead to questions about the way that individual needs, preferences and dispositions are accommodated. To some of the teachers that we talked to, adapting the environment of the classroom or school to meet the needs of the young children transferring to school appears idealistic or too difficult to contemplate and it must be acknowledged that it offers a considerable challenge, especially when viewed from the perspective of one more used to adopting a 'medical' approach. However, not taking steps to ensure that all children are included runs the risk of some members of the class becoming disaffected with education at a cost to them and to society (Sylva \& Evans, 1999; Cox, 2000).

One of the teachers that we interviewed had gone some way towards adopting a responsive, accommodating, social model approach, although she described it as a pragmatic rather than ideological move. She had identified some aspects of classroom life that would be difficult for the children who would form her P1 class, a high proportion of whom came from an area of social and economic disadvantage. She knew that the children were used to arriving at their pre-school setting ready to choose the activities that they wanted to do and that they had only brief whole group events, arranged towards the end of each half-day session. Furthermore, past experience suggested that the children would often have chaotic periods in their family life and would benefit from a time each day when they could adjust to the school environment. Consequently, this teacher adjusted her daily timetable at 
the beginning of the school year, arranging for the day to begin with a period of free play (choosing from a range of activities set out by the teacher) followed by a brief gathering of the whole class when they worked on the literacy and numeracy intervention programme prescribed. Over the course of the school year the balance of play and teacher-led time changed so that towards the end of the year most of the children's day was adult directed. Although we have no evidence of its impact on all of the children in the class, such an approach does at least attempt to respond to perceived need and is in some contrast to the teacher (quoted above) who set out to impose her regime from the beginning.

\section{Identifying Barriers to Inclusion}

What 'needs' can be identified; what are the barriers to inclusion that children experience when they move from pre-school to primary school? In this section we draw on evidence from our own study and other literature to examine some of the barriers that confront children. Almost all children in Scotland (96\% of four year-olds and $85 \%$ of three year-olds) have some experience of pre-school education; indeed, most have two years' experience. Therefore they come to school with a set of expectations about educational environments. But pre-school and primary school are different educational environments and there are evident discontinuities in the child's experience as s/he moves from pre-school to school (Stephen et al, 2003). The successful way in which many children negotiate the cultural shifts necessary should not diminish the degree of adjustment involved, or the difficulties experienced by those who struggled to adapt.

The ability to make choices and act in a self-directed manner is valued in pre-school but following instructions and responding to adults is given a higher priority in primary school. While some children may relish the move to school, with its accompanying change in status to that of a schoolgirl or boy, others will prefer the pre-school environment and its approach to learning, particularly the opportunity to choose the activities with which to engage. For example, Kevin often said that he hated school and told the researcher that school was 'too hard'. Yet he had gone happily to nursery school. He was recorded as being in a positive affective state on $80 \%$ of the observations that we made over two occasions when he was in pre-school. His mother said that he found having to sit down in class to imposed tasks draining. He complained that he did not get opportunities to choose the more play-like activities he preferred as he was slow to complete his work and choices were only offered when other tasks were completed. His teacher recognised that he was more interested in choosing activities (art, craft and modelling in particular) than in doing schoolwork and following a more formal timetable. She was surprised that he was not happier at school as his record from pre-school was good and he had seemed motivated and keen to show her round when she visited him there. Kevin said that he liked colouring in and reading a favourite book best 
and grumbled about work being 'too hard'. He was vulnerable, often in trouble because of his behaviour and was at risk of becoming disengaged from school. Although he made progress with learning during P1, his teacher was not confident that he would cope well with the move to P2, particularly if he were placed in a larger class.

For some, the change in the nature of the relationships prevalent in school was more important than the change in the nature of the learning environment. Hunter missed the warmth and cuddles he had enjoyed in his private nursery and Susie found the lack of personal attention difficult when she moved to school. Pre-school practitioners, particularly in the private nurseries that children in the sample attended, valued a relaxed environment where staff and children knew each other well and more intimate relationships could flourish. However, in primary school teachers wanted children to recognise the authoritative nature of the teacher's role and to be able to move from informal relationships with adults to more formal relationships.

Classroom life in Scotland favours confident, emotionally independent children who are willing to cooperate with other adults and children and who can put aside their personal preferences without evident displeasure. In preschool settings, children's choices during free play give them considerable freedom over the children with whom they develop and maintain relationships and the emphasis in these settings is more on individual relationships than belonging to a distinct group or class. In contrast, P1 classrooms put a premium on mixing well with all children, on working and playing well in teacher allocated groups and on the class as a unit of belonging. Children are expected to be willing to respond when addressed in whole class groups or individually.

These institutional characteristics make it difficult to include in the primary classroom a child whose personality or stage of social and emotional development is not, in school terms, ideal. A child who prefers to work alone, who is reluctant to speak in a group, who needs adult reassurance about his or her work or who speaks little to his or her teacher is at a disadvantage and can be considered as a 'problem' by their teacher. There were examples of these barriers in our sample. Paul and Daniel needed adult reassurance that their work was correct, demands that could only be met because there was more than one adult in the classroom. Both Claire and Charles were happier working and playing alone, a situation that was thought of as problematic by their teachers. For instance, their reluctance to talk, particularly in a group, hampered the way in which their teachers expected to assess their engagement in class activities and the progress of their learning.

Just as children's educational experiences and expectations derived from their pre-school settings may not be a ready match for the school setting, so too their social skills and expectations (built up from their experience of life in the family and community) may or may not transfer well to the school setting. In a stratified society 'school ways' are not necessarily those of the community in which the school is located. Brooker (2002) writes persuasively about the 
experience of children from a poor inner-city neighbourhood (half of them Bangladeshi) in terms of their social and cultural capital and the limits of its value on transfer to school.

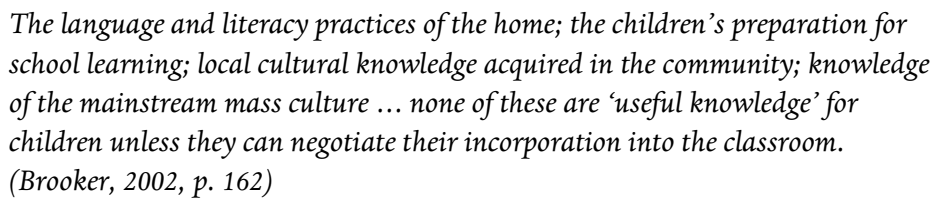

She describes how 'structural variables' in society (referring to the 'familiar triumvirate of race, sex and social class') influence the experience of transitions and, she argues, the outcomes of education. Cultural and social diversity can leave children (and parents) unprepared for the instructional and regulative discourse of school, with rules and expectations that are not made explicit but without which children cannot begin to make progress. Although the school where Brooker conducted her study adopted the rhetoric of inclusion, she concluded that the classroom experience was based on an exclusively Western perspective on childhood and learning. This presented a barrier to participation for children caught between the expectations of their teachers and the advice and prescriptions of their parents.

Our opportunistic sample did not offer the contrasts in home experience that Brooker found. The families in our study were much more like those that she describes as sharing in the school's understanding of play, pedagogy, discipline and developmental goals. Five children in our sample came from minority ethnic backgrounds. The parents of three of these children had been born in Scotland and had attitudes to their children's development and education that differed little from the other middle-class parents in our sample. The parents of two children were Chinese. Both parents in one of these families held academic posts in a university and were immersed in the culture of school. The second Chinese family were keen to adopt the culture of school but were anxious that their son would experience cultural differences, particularly in terms of relationships with teachers, when they returned to China at the end of P1. One family in our sample did challenge the school's code on acceptable behaviour and language in class and felt that their daughter was disadvantaged because they did not share the religious perspective that underlay the school's ethos and approach to discipline.

We did have rather more evidence of social class differences. Children from middle-class homes were supported through transition by parents who were willing and able to seek out their child's class teacher or correspond via the homework record book if they had any concerns. In general, their parents had more differentiated expectations about progress in school and had tracked and supported emerging numeracy and literacy skills during the pre-school period. These parents were ready to play a proactive part in the home-school relationship in a way that other parents (although keen for their children to make progress, delighted by their success and sharing the approach to 
education advocated by the school) were not. For instance, Dean's family life was disrupted during his first year in school when his parents separated and arranging care for the children after school was difficult because of their parents' working hours. In retrospect, his teacher was aware that the relationships with adults offered in school had not met his needs. He had become more 'clingy', less mature and sought a secure attachment to an adult. His family did not discuss the difficulties that he and his brothers were experiencing with school staff. The way in which Dean's family left him to cope alone with his reluctance to leave his father and go into school contrasts with the behaviour of another father who, when his son found lining up to enter school intimidating, lined up with him and accompanied him to his classroom for a number of weeks until he was confident enough to cope alone.

Economic as well as social inequalities will influence children's experiences as they begin school. For example, one child, Kylie, had not attended the nursery class at her local school because only a more distant local authority nursery school offered early morning provision (while her mother worked) at a cost that her family could afford. Her teacher described her as being at a disadvantage as she did not know the school routines as well as her classmates who had been at the school nursery class, and did not benefit from having existing friends in her primary school class.

\section{Conclusion}

We have argued above that looking at approaches to transition through the 'inclusion lens' and, in particular, considering the individual/medical and social model dichotomy offers a useful way of exploring the experiences of children and the ways in which teachers construe their task. By adopting a social model approach it is possible to identify institutional barriers that may impede a child's ready inclusion in the primary classroom. As such, this moves away from the risk that children are 'blamed', or dismissed as problematic, because aspects of their personality, behaviour or preferences do not fit with the provision offered by schools or the way in which teachers construe their role. Locating the difficulty in the child risks embarking on a 'self-fulfilling prophecy'. A child considered early in school as 'a problem' or to be lacking in some key characteristic is likely to be increasingly marginalised and to act and be reacted to in ways that arise from that first diagnosis or labelling. In addition, looking beyond individual pathology allows the structural barriers inherent in society to be recognised along with issues of ethnic and cultural diversity. It focuses on the interaction between the child and the learning context and on the child as an active agent in the classroom rather than a passive participant. Nevertheless, it is the way in which institutions respond to the identification of these barriers that will make a difference to children's experience.

For change to come about teachers will have to become convinced of the advantages of looking beyond individual pathology as an explanation for a 
child's less than ideal fit with his or her teacher's classroom expectations. They will have to be willing to think about aspects of the school environment and culture that are difficult or uncomfortable for children given the educational, family, social and cultural experiences that they have had before starting school. Encouraging teachers to adopt a proactive stance as researchers actively exploring barriers to inclusion through knowledge exchange with the child, his or her parents and other practitioners who know the child well would begin this shift.

But identifying barriers will not be enough to initiate change. A further step is needed. It will be necessary to consider ways in which the educational environment (including cultures of practice and pedagogy) that schools offer can be changed to accommodate all children if some at least are not to become disaffected with and disengaged from learning almost before their time in school has begun. However, the constraints and demands that arise from teaching in a 'target driven' institutional culture may present obstacles to adaptation that many teachers are reluctant to challenge or find impossible to overcome at an individual level. Advocating change in schools is much easier than establishing what and how changes should be made. And the needs of each class and each child in the class may be different. It seems clear, however, that any significant change would have implications for the staffing level of early primary schooling, although it is important to note than improving staffpupil ratios at this crucial stage may not necessarily be effective without the accompanying change of ethos. Nevertheless, consideration of how the school might accommodate to the needs of all young children, rather than how the children can either be shaped to fit the institution or risk exclusion, does seem imperative if educational opportunities are to be inclusive. The latter does not, on the face of it, provide an auspicious beginning to the academic careers of 'non-ideal' pupils.

\section{Note}

[1] This research (and the earlier study of all-day provision) was funded by the Scottish Executive Education Department.

\section{References}

Barton, L. (1997) Inclusive Education: romantic, subversive or realistic? International Journal of Inclusive Education, 1, pp. 231-242.

Bernstein, B. (1996) Pedagogy, Symbolic Control and Identity. London: Taylor \& Francis.

Brooker, L. (2002) Starting School: young children learning cultures. Buckingham: Open University Press. 
Cox, T. (2000) Pupils' Perspective on their Learning, in T. Cox (Ed.) Combating Educational Disadvantage: meeting the needs of vulnerable children. London: Falmer Press.

Fabian, H. (2002) Children Starting School. London: David Fulton.

Margetts, K. (2002) Planning Transition Programmes, in H. Fabian \& A-W. Dunlop (Eds) Transitions in the Early Years. London: RoutledgeFalmer.

Oliver M. (1996) Understanding Disability: from theory to practice. London: Macmillan.

Scottish Consultative Council on the Curriculum (SCCC) (1999) A Curriculum Framework for Children 3 to 5. Dundee: SCCC.

Scottish Executive Education Department (2001) The National Priorities in School Education. http: / /www.scotland.gov.uk/education/nationalpriorities

Scottish Office Education and Industry Department (SOEID) (1997) Curriculum Framework for Children in their Pre-school Year. Edinburgh: SOEID/HMI.

Stephen, C. \& Cope, P. (2003) Moving on to Primary 1: an exploratory study of the experience of transition from pre-school to primary

http:/ / www.scotland.gov.uk/library5/education/ins3-00.asp

Stephen, C., Brown, S., Cope, P. \& Waterhouse, S. (2001) All-day Provision for 3and 4-Year Olds: the experience of children, parents and practitioners. Stirling: University of Stirling.

Stephen, C., Brown, S., Cope, P. \& Waterhouse, S. (2003) Moving from All-day Provision to Primary School. Stirling: University of Stirling.

Sylva, K. \& Evans, F. (1999) Preventing Failure at School, Children and Society, 13, pp. 278-286.

Wilkinson, J.E., Watt, J., Napuk, A. \& Normand, B. (1999) Tracking Children's Progress: record keeping in the pre-school year, in V. Wilson \& J. OgdenSmith (Eds) Pre-school Educational Research: linking policy and practice. Edinburgh: Scottish Executive Education Department.

CHRISTINE STEPHEN is a Research Fellow in the Institute of Education at the University of Stirling. Her research focuses on pre-school provision, cultures of practice and the ways in which children experience educational provision. Correspondence: Dr Christine Stephen, Institute of Education, University of Stirling, Stirling FK9 4LA, United Kingdom (christine.stephen@stir.ac.uk).

PETER COPE is Professor of Education and Head of the Institute of Education at the University of Stirling. His research interests are in professional education, the development and culture of communities of practice and the teaching and learning of musical instrument playing. 